\title{
Duas metáforas históricas sobre o problema do sentido da ação
}

\author{
Ernesto Mora Forero \\ https://orcid.org/0000-0003-1045-6493
}

Introdução

$\mathrm{Na}$ introdução de Economia e sociedade, Max Weber expõe as linhas diretrizes de seu pensamento metodológico. Nelas está contida a que seria uma das ideias mais influentes na história da teoria social. Trata-se do problema da atribuição de sentido da ação como a unidade básica da análise sociológica. Por atribuição de sentido entende-se: (1) o sentido que os agentes atribuem às suas próprias ações, ou (2) o sentido que atribuímos às ações dos outros.

Geralmente, as perguntas sobre o sentido da ação se elevam a questôes de pesquisa social quando relacionadas com um fenômeno necessitado de explicação. Por exemplo, por que indivíduos em grandes cidades usam o carro para ir ao trabalho, se muitas vezes dificulta em vez de facilitar seu deslocamento? Por que o empresário capitalista (clássico) não usufrui os dividendos que lhe proporciona o seu trabalho, mas tem a tendência de acumulá-los? Ou por que, em tempos de crises econômicas e políticas, os cidadãos têm afeição por lideranças autoritárias?

Neste artigo tratarei menos dos elementos centrais dessa ideia no pensamento de Max Weber, e mais de parte do seu destino no decorrer do século xx. Essa história pode ser descrita por meio de duas metáforas abrangentes. Tais metáforas servem 
de guarda-chuvas intuitivos para encontrar conexões filosóficas e epistemológicas entre disciplinas que, de outra maneira, pareceriam desligadas entre si. São elas "a mente como um computador" e "o mundo como um texto".

Para compreender melhor o funcionamento das duas metáforas, é importante lembrar o trabalho de formalização do problema da atribuição de sentido feito por Raymond Boudon em seu "modelo cognitivo de ação" (Boudon [1992] 1995, pp. 27-64; 2001, pp. 121-124). Para Boudon, o objeto central da análise sociológica são os enunciados racionais de ação. Estes podem ser generalizados e formalizados segundo o seguinte modelo:

Um/uns agentes $\mathrm{X}$ fazem a ação $\mathrm{Y}$, nas circunstâncias $\mathrm{P}$ porque consideravam como válidas as razões $\mathrm{R}$.

O trabalho do sociólogo é, em primeiro lugar, construir em modo de hipótese esses enunciados preenchendo os espaços das variáveis. Por exemplo, os agentes nas cidades usam o carro quando vão ao trabalho porque acreditam que chegarão mais rápido, ou porque lhes oferece status social. Ou os primeiros empresários capitalistas em sociedades industriais não usufruem da maioria dos dividendos de seu trabalho, mas os acumulam porque consideram o gasto um pecado.

A variável central na obra de Weber é certamente a variável $R$ : quais razões os agentes dão para justificar as suas ações, ou quais razões atribuímos a eles. Da forma como se preenche a variável $R$ depende a construção das hipóteses mais relevantes sobre o comportamento dos agentes. Segundo Weber, a variável $R$ pode ser preenchida de quatro maneiras: pelos interesses que persegue o agente (racionalidade instrumental), pelos valores que o agente subscreve (racionalidade axiológica), pelas tradições nas quais o agente está imerso, ou pelas "razões" afetivas que atribuímos a eles (Weber [1922], 1984; Schluchter, 1981; Habermas [1981], 2010; Boudon, 2001).

As duas metáforas de que falamos podem ser diferenciadas pela maneira como a variável $R$ é preenchida. Isto é, segundo o modo como entendem a racionalidade dos agentes.

Por um lado, as disciplinas cobertas pela metáfora da "mente como um computador" têm a tendência a reduzir as variáveis de $R$ ao mínimo. Isto é, contemplar apenas um dos valores de $R$. Especificamente o interesse do agente. Por outro lado, as disciplinas cobertas pela metáfora do "mundo como um texto" têm a tendência de multiplicar os valores de $R$ ad infinitum. Isto é, assumir como válido qualquer enunciado de sentido, seja este oferecido pelo próprio agente ou pelo pesquisador.

Neste artigo proponho-me a descrever de modo geral os supostos de ambas as tendências, alguns dos seus principais problemas epistemológicos e as possíveis 
soluções a eles. Tais soluções passam por uma tomada de posição séria a favor da interdisciplinaridade. A pergunta pelo sentido precisa de um diálogo aberto em seus achados e em seus métodos não somente com as ciências sociais, mas especialmente com as ciências biossociais.

\section{A mente como um computador}

Esta metáfora foi utilizada pela primeira vez quase de modo literal pelas primeiras versões da psicologia cognitiva e sua herdeira, a inteligência artificial (IA, na sigla em inglês). Trata-se de uma analogia entre um elemento imaterial, "a mente" (o software), e um elemento material, o corpo ou cérebro (o hardware). O software se entende como um pacote de instruções, pelo geral, uma série de combinações binárias ou de algoritmos que indica a um hardware o que deve fazer. O sonho básico da IA em sua origem era construir computadores capazes de pensar e agir como os seres humanos. Para isso elaborou sofisticados pacotes de instruções, sem se importar muito com o papel dos receptáculos ou hardwares (Sloman e Fernbach, 2017).

Na verdade, a metáfora da mente como um computador é uma versão recente de uma doutrina antiquíssima. Trata-se do velho dualismo metafísico entre uma substância pensante, a alma, e uma substância sensível, o corpo. Entre o pensamento e suas ideias e os sentidos e as percepções. O dualismo metafísico encontra-se já na filosofia pré-socrática e no platonismo, e é compartilhado também quase uniformemente por todas as chamadas religiões axiais (islamismo, hinduísmo, budismo, cristianismo). Ele se insere na modernidade filosófica especialmente através de Descartes e a tradição idealista. O seu postulado central é que a vida consciente depende de um princípio ativo que anima uma entidade material passiva (Armstrong, 1968; Kim, 2002; Bunge, 2010).

Na IA clássica a alma imaterial está formada por uma série de algoritmos que poderiam rodar em qualquer artefato com a suficiente capacidade de memória. Múltiplas tarefas de cálculo podem ser transferidas de um artefato a outro, em qualquer circunstância ou contexto. Nesse sentido, os algoritmos podem ser desenhados com independência do hardware em que são implementados. Essa é a tese básica do chamado computacionismo (Sejnowski et al., 1988; Dennett, 1991; Churchland e Sejnowski, 1993; Gallistel e King, 2009).

A metáfora é herdeira do racionalismo idealista, na tradição platônica e kantiana. É esta uma filosofia que entende a razão como uma série de operações funcionais universais e a priori. Essas operações estão determinadas de uma vez e para sempre. Isto é, estão definidas antes das possíveis variações que pudessem sofrer nas mudanças evolutivas dos organismos que as executam. Em poucas palavras, elas predeterminam 
tanto os sujeitos capazes de alocá-las, quanto os entornos naturais e sociais que eles habitam.

Relacionada com o problema da atribuição de sentido, a metáfora traduz as operações funcionais em enunciados de ação. Estes são perfeitamente transferíveis a qualquer indivíduo, em qualquer situação e em qualquer tempo. Os enunciados que mais facilmente têm cumprido essa função teórica são os chamados instrumentais. Tais enunciados representam os caminhos mais eficazes que utiliza um agente para atingir algum bem esperado. Segundo os enunciados instrumentais, os agentes perseguem, em todo momento e circunstância, maximizar os seus próprios interesses, utilizando os meios mais efetivos para isso. Em geral, esses enunciados são definidos como "racionais". De modo que todo ente material que permita rodar enunciados maximizadores deve ser considerado como racional.

Várias disciplinas podem ser cobertas pelo guarda-chuva dessa metáfora: além da primeira versão da inteligência artificial (Newell, 1982; Fodor e Pylyshyn, 1988; Boden, 2014), a primeira versão da psicologia evolucionária de base inteiramente genética (Cosmides e Tooby, 1987; Dawkins, 1976; Buss, 2004), a sociologia analítica (Epstein, 2007; Axtell, 2000; Agassi, 1975; Elster, 1982; Coleman, 1986) e a teoria da escolha racional e sua modelagem baseada na teoria de jogos (Becker, 1976; Hechter e Opp, 2001; Hogarth e Reder, 1987; Moll e Hoque, 2006; Oppenheimer, 2010).

Em termos culturais, aquela que mais sucesso obteve foi a Teoria da escolha racional (RCT na sigla em inglês). Segundo a RCT, os fatos sociais podem ser explicados sempre desde o ponto de vista dos atores individuais. No caso de que esses fatos envolvam aspectos econômicos, demográficos, políticos, institucionais ou culturais, eles devem ser sempre entendidos como o agregado de decisões individuais. As teses sobre decisões coletivas ou de funcionamento sistêmico são, portanto, minimizadas ou, simplesmente, descartadas.

Na RCT as decisões individuais são construídas segundo a fórmula de ação: todo agente procura sempre maximizar as suas utilidades esperadas sob algumas coerções inerentes à situação na qual se encontra. Essa fórmula de ação é o software que será sempre rodado nas decisões econômicas dos indivíduos. Sempre que um agente escolhe o caminho mais eficiente para atingir o seu próprio interesse, está rodando o software racional do qual vem dotado naturalmente.

A simplicidade da fórmula permite aos teóricos da RCT construir elaborados modelos matemáticos de representação de ações. Ela tem duas consequências gerais. Primeiro: que todas as atividades econômicas sejam entendidas como a interação de, ao menos, dois agentes maximizadores que tentam satisfazer as suas utilidades esperadas. Segundo: que todos os fatos sociais possam ser entendidos como fatos 
econômicos. Isto, dado que a alocação de tais utilidades é arbitrária e pode ser aplicada a qualquer aspecto da vida social.

Assim, todo fato econômico ou social deve-se analisar, em primeiro lugar, definindo um tipo de utilidade. Esta pode ser um bem material específico, um tipo de desejo psicológico, ou um propósito atribuível a alguma ação. Se sabemos qual é essa utilidade, podemos preencher a variável $R$, pois os agentes que a escolheram já podem rodar o software racional que consiste em maximizá-la. Isto é, supondo-se obter a maior quantidade de utilidade que puder atingir com seu agir.

Em segundo lugar, deve ser invocada uma situação de ação na qual se apresenta uma série mínima de alternativas ou variáveis de percursos de ação. Desse modo, pode-se inferir qual seria o caminho mais eficiente. Essa simulação implica o suposto de que outros agentes concorrem pelo mesmo bem. Nesse caso, o software já vem pré-desenhado com uma série finita de alternativas. Entre estas, só uma, fazendo o cálculo das expectativas concorrentes, passa a considerar-se a ideal para cada ator.

Finalmente, quando é disputado um recurso ou bem finito, as expectativas de utilidade de cada agente vão se contrapor com as de outros agentes. Dessa forma, cada agente singular terá proporcionalmente uma certa diminuição de suas utilidades. Assim, afinal, essas limitações espontâneas dos intercâmbios resultarão em um equilíbrio do sistema. As leis do mercado, especialmente a oferta e a demanda, expressam esse mecanismo de equilíbrio entre as vontades contrapostas nas interaçôes sociais. O mercado assegura a longo prazo a alocação proporcional de satisfação dos desejos para cada agente singular (Lucas e Sargent, 1981; Shubik, 1984; Sargent, 1987).

O mercado se entende assim como o único mecanismo sistêmico de coordenação das interações sociais. Isto é, o único elemento dos fatos sociais de que podem ser descritas propriedades emergentes das quais carecem os indivíduos (Coleman, 1990). Essas propriedades emergentes do mercado têm sido explicadas em termos de conhecimento. O mercado "sabe" o que os indivíduos não sabem. Os indivíduos contam apenas com o software racional para realizar suas intervenções econômicas. Qualquer outra variável complementária que possa modificar os traços das relações microeconômicas, tais como o emprego, alocação institucional de recursos, assimetrias dos contextos, ou as externalidades ambientais, deve ser descartada como impossível de medição. Pretender fazer ciência sobre esses fatores é um exercício de soberbia (Hayek, 1944; 1989).

Dessa maneira, o mercado passa a ser o único entorno possível para os agentes sociais. Ele é comumente associado à "imperturbabilidade" dos entornos naturais. Esse entorno "espontâneo" do mercado tende-se a contrapor a qualquer tipo de desenho institucional "artificial" (Ridley, 2015). Para a microeconomia neoclássica esses sistemas artificiais que tentam disputar a "sabedoria" do mercado ameaçam 
perturbar o seu bom funcionamento. Portanto, costumam ser minimizados em toda modelagem do software.

Se o mercado é o único mecanismo supraindividual de coesão e coordenação de ações, então todo campo de atividade pode ser analisado como se fosse um mercado. A RCT não somente facilita o problema interpretativo do sentido das ações sociais, ela também permite um modelo formal explicativo para todas as ciências sociais. Se estendermos o sentido da metáfora, o mercado viria a ser uma rede computacional homogênea com a capacidade de interligar todos os softwares rodados em unidades individuais.

O estudo sistêmico da sociedade depende dessas poucas variáveis que governam essa rede computacional. Quem levou mais longe esses exercícios de transposição das trocas econômicas a todas as formas de interação foi Gary Becker, que ofereceu explicações para muitos dos mais variados fenômenos da vida cultural, espiritual, afetiva e política dos indivíduos (Becker, 1964; 1976).

A RCT tem vários problemas lógicos e epistemológicos que fazem difícil sua corroboração empírica e questionável sua aplicabilidade. Pode-se descrever o principal empecilho fazendo uso da metáfora do software racional. Podemos imaginar os modelos matemáticos das trocas econômicas como um videojogo de realidade virtual. Nele os participantes compartilham um mesmo entorno construído sempre com os mesmos supostos e cenários. Pressupõe-se um tipo de utilidade esperada que é comum a todos os jogadores, e se parte da base de que todos eles tentarão maximizá-la. A informação sobre os modos de obtenção, o estoque dos bens representados pela expectativa de utilidade e os valores de troca são conhecidos por todos. Toda troca entre concorrentes racionais devidamente informados supõe um limite aos desejos de cada indivíduo. Portanto, o jogo por si só tenderá a se manter em equilíbrio. Assim se permitirá a cada jogador o ganho correspondente a suas habilidades como sendo mais ou menos racional que seus adversários.

O grande problema desse videojogo é que nenhum de seus resultados pode ser inferido em um entorno diferente. Não é possível jogá-lo com outros supostos e cenários. Podemos tomar qualquer uma das afirmações da RCT e considerá-la como uma conclusão lógica de todas as outras. Podemos dizer que os agentes são racionais porque, em ambientes de concorrência por recursos limitados, eles procurarão maximizar os seus benefícios até onde o sistema de trocas o permita. Ou podemos dizer que o mercado tenderá ao equilíbrio porque a livre concorrência de agentes interessados, mais cedo que tarde, provocará a diminuição da utilidade marginal de cada um deles.

Em termos lógicos, a RCT dá por concluído o que já sempre esteve contido nas premissas. As conclusões da RCT são em sentido estrito tautologias. Nenhuma das suas informações se suporta em observações de agentes, entornos ou situações reais. 
Basicamente, ao chamar "racionais" aos agentes sociais, a RCT não está testando as correspondências dos seus supostos com os contextos sociais ou observações psicológicas. Ela simplesmente comprova se as pessoas sabem jogar o seu videojogo. Em resumo, para que o software racional funcione, ele depende de que os seus supostos sejam isolados tanto de outras dimensões do comportamento dos indivíduos, como dos entornos que eles habitam. A RCT só é consistente em um vácuo individual e social.

A RCT só pode ser entendida em um vácuo individual porque a ideia de uma racionalidade maximizadora ubíqua espacial e temporalmente não corresponde a nenhuma observação psicológica. Pelo contrário, quando o postulado foi testado experimentalmente, tem-se demonstrado que o comportamento racional (nos termos da RCT) é causalmente dependente de outros sistemas psicológicos como a percepção, as sensações e, em especial, as emoções (Kahneman e Tversky, 1979; Phelps, 2006; Sloman e Fernbach, 2017, p. 105). Não somos racionais o tempo todo. De fato, não o somos a maioria das vezes. A psicologia experimental mostra que muitas pessoas, em situações de decisão econômica, são incapazes de identificar corretamente as opções que têm perante si ou avaliá-las corretamente (Kahneman et al., 1982).

O software racional é uma falsa entidade metafísica, feita de uma vez e para sempre. Ela é "instalada" em humanos e artefatos para lhes dar vida, do mesmo modo como a alma, mente ou a inteligência "anima” nossa matéria corpórea. Porém, contrário do dogma dualista, os indivíduos são entidades biossociais. Organismos surgem devagar através de gradativas acumulações de variáveis funcionais. Estas são herdadas de seus ancestrais e modificadas culturalmente. Sistemas perceptivos, emotivos, sensoriais e cognitivos são o produto de milhares de anos de seleção natural e cultural. A ação conjunta da genética com a aprendizagem social modifica tanto a performance quanto a funcionalidade das estruturas orgânicas (Hebb, 1949; Bunge, 2010, p. 233; Marcus, 2004).

A atribuição de sentido para as ações deve-se considerar como uma propriedade emergente desses sistemas. Portanto, não é possível uma ciência do sentido da ação sem uma indagação sobre o histórico dessa emergência. Isso porque a racionalidade ou irracionalidade resultante é o seu produto. A ciência do sentido deve gerar hipóteses sobre esses sistemas e se engajar na sua comprovação empírica. É preciso integrar os postulados e descobertas das ciências que se ocupam dos subsistemas do comportamento (psicologia cognitiva, psicologia moral experimental, neurociência e teoria evolutiva). Em resumo, não é possível deduzir o sentido da ação dos indivíduos no vácuo individual do software racional.

Mas a RCT só pode também ser entendida em um vácuo social por duas razões. Por um lado, por uma naturalização do mercado como o único sistema organizador da vida social. Por outro lado, pela moral implícita nas "leis" do mercado, graças à 
entrada pela porta dos fundos de sistemas valorativos não declarados no modelo do software racional.

No primeiro caso, a RCT precisa escurecer todas as possíveis explicações alternativas de coordenação de ação que provêm de outros sistemas (filial-parentesco, morais, culturais, institucionais e políticos etc.). É comum a RCT e a economia neoclássica apelarem para supostos princípios de teoria evolutiva. Estes explicariam a organização social como produto da ação espontânea do mercado como mecanismo análogo da seleção natural.

Os fundamentos desta tese remontam a versões pseudocientíficas da teoria evolutiva como o chamado darwinismo social, ou às primeiras versões da psicologia evolucionária (Tiger e Fox, 1971; Hernstein e Murray, 1994; Marks, 2002). Esta última teve um enorme sucesso cultural graças ao livro de Richard Dawkins, Ogene egoísta. Nele se estabelece o egoísmo como o mecanismo funcional de todo processo adaptativo, partindo desde sua base molecular. O genoma é a unidade básica da seleção natural, não os organismos e as agrupações. Porém, a única opção para que essa tese possa ter confirmação empírica é isolando os genes de suas variações no meio ambiente, entre as quais se encontram as formas de socialização, não só dos humanos, mas de qualquer espécie com capacidade para aquilo (Cavalli-Sforza e Feldman, 1981; Richerson e Boyd, 2005; 2010; Wilson, 2015).

Segundo a primeira versão da psicologia evolucionária, os nossos comportamentos racionais egoístas estariam quase totalmente estabelecidos desde o pleistoceno. Porém, o acúmulo de evidência em modelagens e amostras populacionais após esse período confirma inúmeras variações adaptativas inexplicáveis segundo o software racional (Richerson e Boyd, 2005). Nem os mecanismos psicológicos para a inovação, nem a diversificação das produções, nem a divisão do trabalho puderam se dar, sem formas de organização pró-social além do sistema de trocas. Só as pesquisas multinível, isto é, as que tomam em conta como base de análise não só os indivíduos, mas também os grupos e os sistemas sociais, podem explicar tais fenômenos. Na verdade, são fortes necessidades de cooperação grupal para a solução de tarefas as que podem explicar esses grandes pulos adaptativos em termos cognitivos (Richerson e Boyd, 2005; Bowles e Gintis, 2011; Richerson e Henrich, 2012).

A conclusão mais importante que se depreende disso é que o mercado não é o mecanismo primordial que coordena as interações de agentes racionais. O mercado é um produto social, um sistema emergente da facilidade pró-social da espécie humana para a cooperação (Liu e Hanauer, 2011). Inclusive, pode-se dizer que o mercado não é, nem sequer, o principal sistema a ser tratado pelos estudos econômicos. Trata-se de um subsistema econômico, entre outros tais como o trabalho, os recursos naturais e as instituições (Polanyi et al., 1957; Granovetter, 1985; Swedberg, 1994; Bunge, 1999). 
No segundo caso, a mistificação do mercado, como se estivesse ausente de sistemas valorativos, faz parecer como se os seus mecanismos funcionassem de modo espontâneo e automático. Entretanto, a defesa dessa tese está atrelada a matrizes morais que influenciam as práticas e a formação de identidades. Ela costuma oferecer um conjunto estável de preferências sociais de fácil uso para os agentes. Dessa maneira lhes evita lidar com decisões difíceis e abstratas, próprias de sociedades complexas.

Geralmente esse decálogo moral se compõe de valores que se predicam dos indivíduos como sendo "livres". São eles, por exemplo, a eficiência individual, a formação do caráter e a não dependência das instituições. Os valores coletivos próprios de organizações são, pelo contrário, não tematizados e construídos em analogia com os valores individuais. Assim, o gasto social das organizações públicas deve ser visto como espelho do gasto individual e familiar. Ao mesmo tempo, o software racional, competitivo por definição, define as práticas de toda organização coletiva (Turchin, 2016, pp. 45-66). A mistificação do mercado implica no final a condenação de formas de intenção coletiva e sentimentos básicos da cooperação: solidariedade e coesão (Fehr e Fischbacher, 2003; Gintis et al., 2005; Mathew et al., 2013).

\section{0 mundo como um texto}

Esta metáfora tem uma origem mais explicitamente religiosa. Ela envolve os saberes profissionais ligados ao estudo das escrituras bíblicas. A disciplina profissional específica para a compreensão dos textos bíblicos na alta Idade Média e na Reforma foi conhecida como hermenêutica, integrando uma série de técnicas para fazer a "correta" interpretação das mensagens decorrentes das histórias, dos poemas e das reflexões dos textos sagrados (Grondin, [1991] 1994). O trabalho do hermeneuta era "traduzir" essa mensagem inserida nas simbologias das escrituras aos termos de uma dogmática que servisse de orientação prática ao crente. Isso implicava a complexa tarefa de distinguir entre os significados literais e alegóricos da palavra divina. A leitura de um universo simbólico se traduz em orientações para a ação, e em um conjunto de preferências para as decisões dos indivíduos (Grondin, [1991] 1994).

Mas muita da efetividade do discurso bíblico depende da substituição dos seus próprios referentes simbólicos, com os referentes da realidade do crente. Assim, o mundo em que se age é o "mundo" discursivo dos textos sagrados. Esse solapamento de referentes se apoia na ideia comum a muitas religiões de que as palavras da divindade criam realidades. Do "primeiro foi o verbo" se passa a totus in verba. Portanto, para conhecer o mundo basta estudar os textos, ou ouvir a palavra dos expertos em textos. 
A hermenêutica como disciplina humanista surge nos âmbitos filológicos e filosóficos alemães em fins do século Xıx. Em princípio, ela abandona a sua restrição a uma interpretação do mundo e do agir humano a partir das escrituras. Primeiro, ela passa a se preocupar especialmente pelos estados interiores dos autores que criam textos. Especialmente textos históricos, filológicos e literários das tradições clássicas.

A primeira grande ideia da hermenêutica filosófica é que, dado que não temos um acesso direto aos estados mentais dos autores, devemos fazer um rodeio pelo que se chamaria "objetivações textuais”. As objetivações textuais são as manifestações da interioridade dos autores na forma objetiva de escritos, mas aos quais se tem acesso de modo empático, intuitivo e por processos afetivos de identificação. Essa versão da hermenêutica moderna é conhecida como "romântica", e seu principal exponente é o teólogo protestante Friedrich Schleiermacher (1768-1834). Por outro lado, definiram-se certas coincidências afetivas, eletivas ou empáticas entre vários autores de gerações próximas como “visões de mundo". Assim, uma “visão de mundo" se entende como os sistemas de redes simbólicas relevantes a certa cultura em determinado momento, objetivados via textos relevantes. $\mathrm{O}$ pai dessa nova disciplina, como é bem sabido, foi o filólogo e historiador neokantiano, Wilhelm Dilthey (2002, vol. 3, pp. 91-97).

Em um segundo momento, a ideia aplicada aos autores por trás dos textos é estendida a todos os agentes que estão por trás de suas ações. Isto é, entende-se a ação como uma objetivação das intenções, pensamentos e afeções dos indivíduos. Lê-se a ação como um texto (Ricoeur, 1965; 1977; [1986] 2001; Brown, 1987; 1990). Ou, ao menos, através das ações procura-se interpretar os estados mentais das pessoas como se fossem textos. Essa é a base idealista da chamada sociologia compreensiva e do individualismo metodológico, cujo pioneiro é Max Weber. O objetivo central da sociologia compreensiva é poder gerar inferências sobre o sentido (Sinn) que os agentes dão de suas próprias ações (Weber, [1913] 1992, p. 318). Isto é, o foco hermenêutico restringe-se à interpretação dos propósitos, intenções e decisões dos indivíduos para agir.

Em um princípio, essas inferências devem ser entendidas em Weber como hipóteses sobre o comportamento. Isso supõe que elas devem passar pelo crivo da comparação com hipóteses rivais e a comprovação empírica. Contudo, essa advertência característica do proceder científico não foi continuada pelos herdeiros da sociologia compreensiva. Por um lado, estandardizou-se a regra promovida por Dilthey de que as ciências do espírito se entendem só com interpretações e não com explicações (Schütz, [1932] 1967; Berger e Luckmann, 1966; Turco e Zuckerman, 2017). Isto é, elas se atêm aos símbolos e deixam de lado a preocupação com as causas que pudessem produzi-los. E por outro lado, o exercício de 
interpretação se estendeu além dos estados mentais individuais a toda forma de produção simbólica coletiva.

A antropologia cultural, o interacionismo simbólico e a etnometodologia foram além da metáfora da "leitura" dos estados mentais. Essas disciplinas estenderam a leitura de intenções e sentidos como símbolos às comunidades ou grupos humanos. Desde essa perspectiva, os fatos sociais passam a ser construtos simbólicos que tecem redes de significação entre si (Goffman, 1967; 1975; Garfinkel, 1967;2002). Tendo a hermenêutica como base, a interpretação de microrrituais de interação passou a ser um dos eixos centrais da metodologia das ciências sociais. A análise sociológica centrou-se mais nesses sistemas semióticos emergentes que nos próprios sistemas sociais que lhes deram origem. A identificação de todo produto semiótico como fenômeno cultural levou, em primeiro lugar, a uma definição de cultura indiscernível dos objetos simbólicos (Woolgar, 1986). E, em segundo lugar, passou-se a entender todos os fatos sociais como derivados de fatos culturais.

Essa radicalização da cultura como núcleo central da análise social recebe o nome de culturalismo ou contextualismo radical. O seu postulado central consiste em que a verdade das afirmações sobre qualquer grupo humano depende dos significados que esse grupo tem produzido em termos simbólicos (Rorty, 1981; Geertz, 1984; Clifford e Marcus, 1986; Bloor, 1991; Cerulo, 1997; Longino, 2002). O culturalismo é uma corrente idealista porque desconhece todos os fatores materiais (trabalho, recursos naturais, conflito, corpos humanos) que têm incidência na produção desses produtos simbólicos. E é também dualista porque entende as estruturas simbólicas como tendo uma existência independente da infraestrutura biológica, e dos entornos sociais e naturais que as produzem.

O culturalismo exime o pesquisador de qualquer outra metodologia que não seja a interpretação de sistemas semióticos. Igual ao hermeneuta clássico, o culturalista "lê" as populações como se fossem textos. Nesse ponto, é comum que as asseverações sobre culturas específicas deixem de ser meras hipóteses sobre o comportamento para passarem a ser fontes de "verdade”. Essas inferências intelectuais se adicionam às capas de sentido dos povos estudados. À "cultura” das populações é acrescentada a "cultura" interpretativa dos textos literários. E a esta última se acrescenta a "cultura" interpretativa dos pesquisadores como estratos a mais de saber semiótico (Ricoeur, 1975; 1977; 1983; Geertz, 1973; Gadamer, [1975] 2004).

O último e mais radical passo no uso da metáfora lhe devolve a sua versão originária mais religiosa. Trata-se da sua apropriação pelos filósofos pós-modernos e parte da chamada filosofia analítica. Basicamente, a metáfora retoma seu viés literal graças ao chamado giro linguístico que caracterizou as humanidades no último quarto do século passado. O giro linguístico, em termos gerais, radicaliza o equívoco semân- 
tico entre fatos e representações. Já não se trata somente de que os pesquisadores interpretem fatos, intenções ou culturas como se fossem textos. Agora, em termos ontológicos, esses objetos passam a se considerar como meras entidades do discurso. Isto é, não existe nada fora das nossas representações linguísticas. O cientista social retoma o totus in verba do hermeneuta bíblico, ou, em palavras de Derrida, não há nada além do texto (Derrida, 1967).

O "mundo como um texto" expressa, antes que uma metodologia específica, uma habilidade humana para o ordenamento dos fatos do mundo e para ponderar as orientações para o agir. A metáfora adequa-se pelo menos a três finalidades humanas específicas:

- Dar sentido ao universo oferecendo uma ontologia folk dos seus objetos e uma mecânica folk de seu funcionamento.

- Inferir ou "ler" as intenções dos outros e planejar as suas ações em consequência. Isto é, ela descreve uma psicologia folk.

- Criar pontes entre os cânones valorativos das comunidades e as práticas socialmente aceitas dos agentes. Isto é, ela descreve uma sociologia folk.

Todas essas variáveis de interpretação da realidade são, na verdade, capacidades psicológicas. Elas são, de fato, um assunto fundamental e incontornável da pesquisa em ciências sociais. Porém, essas "inferências ordinárias" são generalizadas como interpretações, e esse procedimento é equiparado com a metodologia básica das ciências do espírito. Ao fazer isto, os pensadores hermenêuticos estão simplesmente confundindo os objetos de pesquisa com a pesquisa em si mesma (Watts, 2014). Pois o conhecimento na vida ordinária é casuístico. Ele deriva inferências arbitrárias não só das experiências subjetivas, mas dos múltiplos fatores aleatórios que condicionam essas experiências. Esse conhecimento não pode ser generalizável precisamente pela sua condição de absoluta singularidade. Portanto, não pode especificar os métodos com os quais seja possível provar as suas afirmações (Bunge, 1996).

Por conseguinte, o principal problema da metáfora vem quando deslocada do saber ordinário ao lugar de procedimento básico da pesquisa social. Esse problema se dá, ao menos, em dois equívocos ontológicos. O primeiro no nível dos componentes (agentes e ações), e o segundo no nível dos sistemas que, no caso, compreende apenas o sistema da cultura.

No caso dos componentes, o enfoque hermenêutico confunde o que são indicadores de conduta com os processos mentais que os precedem. Basicamente, falamos de dois tipos de indicadores. Por um lado, os sistemas semióticos (gestos, sinais, ícones etc.). Por outro, as próprias razões verbalizadas, isto é, as proposições de ação que 
expressam as preferências dos agentes. Estas últimas são a unidade básica de análise do chamado individualismo metodológico e a sociologia compreensiva. Qualquer que seja o indicador, a pesquisa sociológica clássica só pode registrar padrões de comportamento. Estes se baseiam em amostras representativas para tentar dar conta de determinado fenômeno social.

Porém, esse tipo de modelo conceitual verificável mediante instrumentos estatísticos e de pesquisa experimental é alheio à tradição hermenêutica. Ela prefere dar interpretações abstratas e gerais sobre a condição existencial dos indivíduos ou a “visão de mundo" de uma época. Mas essas afirmações gerais, ou adivinhações sobre estados mentais coletivos, não se diferenciam do saber ordinário. A razão principal para tal proceder está nos próprios postulados fundadores da disciplina. Segundo a hermenêutica, os cientistas sociais não podem dar "explicações” nas suas análises, pois eles têm a dupla condição de observadores e parte dos fenômenos a serem estudados. Eles tão só oferecem interpretações (Gadamer, 1975; Ricoeur, 1975, [1986]; 2001; Habermas, 1988; 2002).

A confusão radica na base dualista da disciplina que entende os estados mentais como sendo um fenômeno à parte do estudo de organismos vivos. Os estados mentais seriam ideações com um estatuto ontológico absolutamente independente de sua origem material. Sobre essa base nunca se tem um acesso àquilo que as pessoas sentem, pensam, opinam ou desejam. Só temos um acesso indireto a essas ideações pela sua transformação em constructos verbalizados, falados ou escritos. Isto é, textos.

Ao tomar essa via, os hermeneutas renunciam a décadas de acúmulo de evidência na pesquisa sobre o comportamento. Eles tratam os fenômenos da intencionalidade como caixas-pretas que envolvem conteúdos aos quais não se tem acesso. Porém, múltiplos estudos sobre empatia, simpatia, identificação, assunção de papel fazem claramente a distinção entre indicadores e processos mentais (Plutchik, 1987; Preston e De Waal, 2002; Shamay-Tsoory, 2011). Por outro lado, os estudos na chamada "teoria da mente" encontraram consistência no desenvolvimento onto e filogenético de capacidades de "leitura mental", isto é, da capacidade psicológica para antecipar as intenções dos outros e agir em consequência (Tomasello et al., 2005; Baron-Cohen, 2005; Baron-Cohen et al., 2000). Além disso, a descoberta dos chamados neurônios espelho consegue explicar parte do espalhamento de condutas reconhecidas coletivamente, mediante operações adaptativas como a imitação (Iacoboni, 2008; Rizzolatti et al., 1996).

Todos esses estudos se fundamentam em hipóteses causais entre uma infraestrutura material (cérebros e corpos) e as suas manifestações de conduta (indicadores). Por exemplo, perante intuições espontâneas como a vontade de dar consolo a outro, os pesquisadores tentam estabelecer qual sistema psicológico está envolvido, qual a 
função (para o indivíduo ou para o grupo) que tal conduta pode cumprir, além de quais os problemas dos indivíduos com deficiências na produção de tais condutas (De Waal, 2008; Decety e Jackson, 2006). Essas suposições causais hipotéticas são depois corroboradas com os métodos da amostragem estatística sociológica, de experimentação em psicologia cognitiva e do trabalho no laboratório do neurocientista. Sendo assim, o estudo da atribuição de sentido em ciências sociais não pode permanecer no limiar da mera interpretação. Somente a pesquisa multidisciplinar permite ao cientista social conhecer o verdadeiro estado da arte de seus problemas.

No caso dos sistemas, isto é, da noção de cultura, a tradição hermenêutica confunde o que são sistemas simbólicos emergentes das relações sociais e os sistemas concretos como tal. São as pessoas, componentes de sistemas concretos (família, escola, igreja, hospital), as que produzem mecanismos simbólicos de coordenação das ações (Bunge, 1996; 2000). Inclusive, a origem da linguagem consiste em uma sistematização gradativa de uma série de propriedades emergentes dos sistemas sociais (Bunge, 2003).

Quando Habermas postula os pactos comunicativos como a base dos processos de socialização, está simplesmente invertendo a ordem causal da organização grupal (Habermas, [1981] 2010; [1999] 2002). Trata-se de novo da metáfora criacionista do verbo virtual e ideal que antecede as relaçôes sociais reais e concretas. A consequência lógica desse suposto é que as explicações sobre a origem, o funcionamento e as funções dos sistemas culturais são mistificadas. A cultura como rede simbólica passa a ser o horizonte total de todas as possíveis explicações do comportamento e da organização humana.

Nesse enfoque holista da cultura, o próprio termo cultura é deixado sem definir. Renuncia-se assim a qualquer indagação sobre os mecanismos específicos com que operam os sistemas culturais, sua origem e evolução. Isso implica, de novo, deixar de lado todo o acúmulo de evidência empírica sobre os sistemas culturais. $\mathrm{O}$ primeiro assunto a ser descartado é a infraestrutura biológica e evolutiva que fez possível o fato de que sejamos uma espécie com uma forma especialmente sofisticada de cultura (Richerson e Boyd, 2005; Richerson e Christiansen, 2013; Lewens, 2015).

A explicação de uma prática cultural deve incluir quais funções ela cumpre para responder a um desafio concreto de socialização. Por exemplo, como se consegue uma alocação coordenada de papéis em macrossociedades que possuem uma sofisticada divisão do trabalho. Uma explicação desse tipo não deve ficar no limiar da linguagem como meio de coordenação. Ela deve se perguntar também pelas disposições cognitivas que os indivíduos têm que possuir para tais desafios (Dunbar, 2009; 2016; Henrich e McElreath, 2007). Tal é o caso do uso de narrativas morais como dispositivos para a coesão social (Shweder et al., 1987; 1997; McAdams, 2001). A 
transmissão de relatos mediante rituais sociais tem o potencial de gerar padrões de comportamento moralmente motivados.

É este um apelo explicativo a mecanismos discursivos. Porém, ele só resulta efetivo se os indivíduos desenvolveram por via genética um desenho cerebral de produção de intuições morais. Módulos concretos de moralidade são estimulados mediante modelos de representação de ações como são as narrativas (Haidt e Joseph, 2004; 2007; Graham et al., 2011). A variedade das experiências morais dos sujeitos em diversas culturas que o enfoque hermenêutico prega é ampla, mas limitada. Facilmente, qualquer relato fundacional, como mostra a etnografia comparada, cai em três categorias: comunidade, autonomia ou divindade (Shweder et al., 1997).

O culturalismo hermenêutico é incapaz de dar resposta a esse tipo de perguntas. Ele dá por assumido os produtos simbólicos como o "entorno" total que os agentes sociais habitam. $\mathrm{O}$ chamado círculo hermenêutico expressa bem essa incapacidade de oferecer alguma hipótese explicativa do seu principal objeto de estudo: a cultura. O círculo hermenêutico consiste em que a cultura, enquanto rede de produtos simbólicos, se compreende só através de seus próprios produtos simbólicos. Porém, nunca chegamos a saber o que esses produtos são ou de onde vêm.

\section{Convergência das duas metáforas: dualismo, atomismo e holismo}

Os computacionistas e os textualistas costumam ser vistos em tradições opostas. É comum que ambas as tendências sejam etiquetadas de forma antagônica. Se os computacionistas são considerados como calculistas, os textualistas se reconhecem como humanistas. Os primeiros parecem entender os agentes como espécies de comerciantes. Já os outros os enxergam como criaturas simbólicas. Os defensores do software racional analisam as preferências dos agentes com base nas variáveis mínimas do custo-benefício. Os textualistas deixam tudo ao fluxo da interpretação. Igual acontece com os ataques mútuos. Para os textualistas, os computacionistas são chamados de positivistas. Já para estes últimos, os herdeiros da hermenêutica são simplesmente relativistas.

Contudo, as duas tradições têm muito mais em comum do que comumente se pensa. Como tradições de pensamento, ambas são ao mesmo tempo dualistas, atomistas e holistas. Esses enfoques determinam tanto sua ontologia como sua epistemologia.

Como se disse, ambas as correntes são dualistas. Por um lado, as disciplinas da metáfora computacional partem de um software ideal a priori. Este não sofre modificações com as transformações adaptativas dos organismos que o "rodam”. Variações evolutivas não produzem nenhum efeito no modelo do software. Portanto, trata-se de um modelo alheio à história natural, e incapaz de incorporar a mudança social. 
Por outro lado, o textualismo parte da idealização do discurso como produtor causal tanto dos indivíduos como dos comportamentos sociais. Isto é, dá-se por assentado que a cultura é basicamente uma entidade discursiva que antecede todas as práticas e formas de organização social. Portanto, não podemos aprender nada sobre a cultura olhando o funcionamento do nosso corpo, o cérebro e a história evolutiva dos grupos humanos.

Ambas as tradições são também atomistas, pois as duas lidam ou com indivíduos isolados ou com "particulares culturais". No caso dos computacionistas, o atomismo é óbvio, já que a sua unidade básica de análise é o agente racional. Para os computacionistas, a sociedade é simplesmente a agregação das decisões de indivíduos discretos. Especialmente, a RCT clássica enfrenta qualquer disfunção do sistema mercado como um desajuste nos incentivos ou castigos que modelam as preferências dos agentes. Essas preferências geralmente não contemplam a modelagem da ação coletiva. As formas de ajuste institucional e os mecanismos de cooperação são sempre aspectos derivados e acidentais.

Os textualistas, igualmente, mesmo ressaltando as redes coletivas de saber social, são atomistas, dado seu particularismo e contextualismo extremo. Essas tendências se expressam bem em seu postulado da incomensurabilidade. Não existe uma experiência pessoal igual a outra, nem existe uma cultura, povo, etnia, grupo humano iguais aos outros; portanto, a pesquisa social deve ser sempre orientada ao conhecimento local, absolutamente restrita às condições temporais e maleável metodologicamente para cada caso (Nelson et al., 1992; Grossberg, 1997). Em palavras de Foucault: "em qualquer cultura, em todo momento, tem sempre uma episteme só que define as condições de possibilidade de todo conhecimento", sendo essas epistemes as que "esboçam em seu conjunto a organização geral das ordens empíricas” (Foucault, [1966] 1984, citado por Reynoso, 2000). O postulado da incomensurabilidade pode ser até certo nível óbvio; além disso, falso; e, se aplicado de forma dogmática, incontrastável.

É óbvio que nenhuma pessoa, nem sua história, desejos e afeições são iguais às outras. Mas uma boa porcentagem dessas variações é devida à própria diferenciação genética. Todos os organismos vivos possuem uma infraestrutura biológica básica que os faz únicos. Podemos chamá-la, seguindo a metáfora de Gary Marcus, os rascunhos do livro pessoal de vida disposto pelos genes. Esse livro é imediatamente editado pela cultura e pelo meio ambiente, o qual obviamente acelera e multiplica as variações genéticas (Marcus, 2004).

Contudo, esse fato não diz por que certas variações se dão com maior frequência sob certas condições e contextos. Nem por que certos arranjos socioeconômicos e culturais estão associados a determinados comportamentos (Richerson e Boyd, 2005; Inglehart, 2008; 2018). Entornos sociais criam variações que favorecem a 
adaptabilidade do grupo, melhorando a qualidade de vida dos seus membros, ao tempo que entornos desfavoráveis podem gerar variações nefastas para os grupos e seus membros (Richerson e Boyd, 2005; Turchin, 2013).

Portanto, é falso que a incomensurabilidade de indivíduos e culturas possa se estender infinitamente. Isso se aplica, inclusive, ao próprio discurso. Todos os textos têm um horizonte de interpretação amplo, mas finito (Eco, 1992; Easterlin, 2012). Isso porque eles são, na verdade, subsistemas, tanto de sistemas orgânicos (indivíduos), quanto de sistemas sociais (grupos). E esses sistemas, orgânicos e sociais, possuem estruturas e formas de funcionamento comparáveis. Os mecanismos comuns desses sistemas, assim como suas variações (incluindo as variações discursivas), devem ser os elementos que integrem as hipóteses da pesquisa social.

Finalmente, o postulado da incomensurabilidade tomado como dogma faz impossível a pesquisa empírica. Isso porque, por um lado, a partir dele não pode ser gerado nenhum enunciado, nem hipótese generalizável, de modo a ser corroborado. E por outro, porque o postulado de incomensurabilidade é, em si mesmo, um postulado generalista extremo. Isto é, ele nega em si mesmo o princípio particularista que alimenta as escolas textualistas. Não há, portanto, um modo de usá-lo sem cair em contradições lógicas e teóricas que fazem impossível sua aplicação (Mouzelis, 1995, pp. 42-45; Reynoso, 2000, pp. 37-39)

No entanto, mesmo sendo atomistas, ambas as correntes são também holistas. Elas apresentam entornos não definidos e insuperáveis que exercem influência de modo absoluto nos comportamentos dos agentes. São esses entornos, respectivamente, o mercado e a cultura.

O mercado, segundo definido pela microeconomia neoclássica, é um entorno com todas as condições de funcionamento predeterminadas (Arrow e Debreu, 1954; Becker, 1976; Coase, 1988). Ele estabelece de uma vez e para sempre as condições de jogo para os participantes que nele estão inseridos. A possibilidade de mudança do mercado é, em teoria, totalmente cega e arbitrária. Aliás, os componentes humanos das estruturas não podem nem devem intervir com o pré-desenho do sistema para garantir o seu equilíbrio natural.

Esse entorno imaginado em analogia com o mecanismo da seleção natural, também cego e arbitrário, não corresponde, contudo, a nenhum sistema concreto. A consequência teórica mais importante disso é a mistificação dos outros sistemas sociais. O sistema mercado acaba ocultando a evolução dos outros sistemas e subsistemas sociais e suas funções adaptativas (Harcourt, 2012). As relações de parentesco, as formas intergrupais de coligação e o surgimento de estruturas complexas institucionais desde as associações voluntárias até o estado são descartados pelos computacionistas como não sendo produtos emergentes da evolução social. 
Por outro lado, a cultura, como um sistema que se interpreta a si mesmo, não permite distinguir as ações dos agentes que superam os marcos dos seus contextos. A leitura das ações dos agentes individuais como simples reflexos do texto da comunidade que habitam acaba por defini-los como presos em cárceres culturais.

Além disso, igual ao computacionismo, o textualismo deixa de lado os diversos entornos que afetam a cultura. Esses entornos incluem as próprias restrições biológicas dos organismos que produzem cultura e a série de condicionamentos sociais e naturais que restringem o livre fluxo de trocas simbólicas. Igual ao mercado, a cultura como sistema absoluto não permite distinguir os subsistemas que funcionam com mecanismos distintos aos da mera discursividade. A administração do poder, a concorrência, a cooperação e a divisão do trabalho não podem depender exclusivamente de habilidades interpretativas ou de leituras subjetivas de símbolos. Elas evoluem também segundo leis regulares dos entornos naturais e sociais. As primeiras, em sua maioria, imodificáveis, enquanto as segundas, produto de milhares de anos de seleção grupal na espécie (Richerson e Boyd, 2005; Jordan et al., 2013).

Algumas soluções ao dualismo, atomismo e holismo na pesquisa sobre o sentido da ação

No espaço deste artigo é impossível responder a todas as limitantes das duas tradições expostas. Elas implicam mudanças substantivas nas concepções ontológicas de base de cada doutrina, e em suas consequências epistemológicas e metodológicas. Eu me limitarei aqui a duas recomendações básicas (primeiros passos) que nós, cientistas sociais, podemos aprender para superar os três dogmas mencionados. Basicamente, sigo aqui os pontos centrais da epistemologia social de Mario Bunge (1996; 2003):

1. Em primeiro lugar é fundamental o aperfeiçoamento dos modelos conceptuais com os quais descrevemos o nosso objeto de estudo. Isto é, qual é a ontologia de base, a mobília do mundo, que nos compete analisar, compreender e explicar. Defendo aqui que o objeto geral do cientista social são sistemas sociais concretos, não seus componentes (atomismo), nem as totalidades (holismo), nem as estruturas (funcionalismo) por si sós; e o objeto específico do problema do sentido da ação são os sistemas de preferências dos membros da sociedade em interação (intenções, interesses, valorações e opiniões).

Isso implica, em primeiro lugar, o estudo dos subsistemas biológicos, orgânicos, cognitivos, semióticos e culturais que permitem a existência desse sistema emergente e explicam os seus mecanismos; e em segundo lugar, o estudo das relações com os macrossistemas que limitam ou possibilitam o funcionamento dos sistemas 
de preferências: o meio ambiente natural, a cultura, a economia, o direito e a política. As explicações que reduzem o sentido da ação a um subsistema só (como o sistema cognitivo-racional, ou o sistema semiótico de produção de símbolos), ou a um macrossistema só (como os sistemas de oferta e demanda da economia, ou os sistemas culturais de poder) geralmente oferecem imagens ideais da realidade social, que ou bem têm se provado como falsas, ou não são falsáveis (intuiçôes ou captações não verificáveis empiricamente), isto é, inúteis para a pesquisa científica. A tomada de posição por um modelo ontológico tem necessariamente consequências nas abordagens epistemológicas e metodológicas. Vou me limitar aqui às duas mais urgentes.

A primeira consequência é o abandono do dogma epistemológico da divisão radical do conhecimento em ciências do espírito e ciências da natureza e suas correspondentes metodologias: a compreensão e a explicação. A clássica divisão entre verstehen e erklärung é, na verdade, um reflexo do dualismo ontológico. Por um lado, a compreensão é uma metodologia orientada aos objetos espirituais ou ideais, enquanto a explicação é uma metodologia orientada aos objetos materiais. Na verdade, compreensão e explicação são apenas momentos (e não os únicos) de toda pesquisa científica. Não só não podem estar desligados, mas também devem ser coerentes entre si. A compreensão refere-se às etapas de intuição, formulação de um problema de pesquisa e construção de um modelo conceptual (pesquisa teórica) a partir das hipóteses primárias e secundárias sobre o sistema que é o objeto de análise, e sobre os subsistemas e macrossistemas que o afetam causalmente. A explicação compreende a validação interna do modelo conceptual e as metodologias e técnicas para dar validez externa e comprovação às hipóteses ou modelo conceptual (pesquisa empírica).

A divisão entre verstehen e erklarung não é um fenômeno histórico do mundo acadêmico do neokantianismo no despontar do século xx. Ela permeia as produções e métodos de trabalho de muitos cientistas sociais até hoje. Essa divisão metodológica está presente, explícita ou implicitamente, tanto no computacionismo quanto no textualismo. São meros objetos ideais os modelos matemáticos do agir racional sem correspondência com nenhuma observação psicológica real. São meros objetos ideais os "espíritos" dos autores, o excesso de interpretação de produtos simbólicos, a adivinhação empática da intenção das ações, ou a captação intuitiva de totalidades culturais.

Esse pressuposto metodológico de base dualista impede que exista qualquer diálogo, comunicação, intercâmbio e coordenação entre os métodos das ciências sociais e as ciências biossociais (psicologia cognitiva, neurociência e teoria evolutiva). Isto é, nega a interdisciplinaridade. 
Entretanto, o problema do sentido da ação é um problema eminentemente interdisciplinar e biossocial. Refere-se a uma função ou sistema funcional específico dos cérebros humanos para a formação e coordenação de grupos sociais: os sistemas que permitem ter intençôes, que relacionam percepções e intuiçôes de ação com propósito e planos; os sistemas que nos possibilitam antecipar os comportamentos dos outros e nos permitem atuar em consequência, como o desenvolve a chamada teoria da mente (Tomasello et al., 2005; Baron-Cohen, 2005); os sistemas que nos permitem ter capacidade de empatia e solidariedade e, portanto, ter formas de organização social (cooperação) (Preston e De Waal 2002; Shamay-Tsoory, 2011; Wilson, 2008); os sistemas que permitem ter capacidade para a competição individual ou grupal e que fundamentam o desempenho e os limites do poder (Wilson, 2008; Turchin, 2013); os sistemas que nos possibilitam ter intuições morais e, portanto, ter semelhanças e variações em termos de valores entre grupos humanos (Haidt e Joseph 2004, 2007); os sistemas que nos permitem ter variações acumulativas por aprendizado (isto é, por via não genética) a partir de competências para a socialização como a imitação e a inovação, isto é, que nos permitem ter cultura (Richerson e Boyd 2005) etc.

A segunda consequência metodológica é a atestação de que nenhum constructo conceptual ideal substitui a pesquisa empírica. Muito menos aqueles baseados em dogmas atomistas ou holistas. Nem a beleza na sofisticação de modelos matemáticos sobre os comportamentos dos agentes racionais ou o equilíbrio dos mercados; nem o poder retórico de tratados que mostram imagens de totalidades sociais exclusivamente grudadas por dispositivos de poder. $\mathrm{O}$ teste dessas proto-hipóteses tem mostrado ou que são só muito parcialmente verdadeiras (geralmente exagerações de algumas proposições verdadeiras), ou simplesmente falsas, ou inverificáveis.

2. A segunda recomendação é mais fácil para nós: ler. Quando falamos que a explicação de um sistema social não pode ser reduzida a um subsistema ou macrossistema, claramente não estamos dando a entender que o cientista social deve ser experto (ontológica, epistemológica e metodologicamente) em todos esses âmbitos vinculados com seu problema. O que isso quer dizer é que, dentro de seu modelo conceptual, o pesquisador deve estar atento a quais subsistemas e macrossistemas têm efetivamente poder explicativo para suportar as suas hipóteses. 
Referências Bibliográficas

Agassi, Joseph. (1975), "Institutional individualism”. British Journal of Sociology, 26 (2): 144- 55.

Armstrong, David M. (1968), A materialist theory of the mind. Londres, Routledge and Kegan Paul.

Arrow, Kenneth J. \& Debreu, Gerard. (1954), "Existence of an equilibrium for a competitive economy”. Econometrica, 22: 265-290.

Axtell, Robert. (2000), Why agents? on carried motivations for agent computing in social sciences. Washington, The Brookings Institution.

Baron-Cohen, Simon. (2005), “The empathizing system: A revision of the model of mind reading system". In: ElLIS, B. \& BJORKLUND, D. (orgs.). Origins of the social mind: Evolutionary psychology and child development. Nova York, Guilford.

BAron-Cohen, Simon et al. (2000), Understandingotherminds: Perspectives from developmental cognitive neuroscience. Oxford, Oxford UP.

BeCKeR, Gary S. (1964), Human capital: A theoretical and empirical analysis. Nova York, Columbia UP.

BeCKer, Gary S. (1976), The economic approach to human behavior. Chicago, Chicago UP.

Berger, Peter \& Luckmann, Thomas. (1966), The social construction of reality: A treatise in the sociology of knowledge. Nova York, Doubleday and Company.

Bloor, David. (1991), Knowledge and social imagery. Chicago, Chicago UP.

Boden, Margaret A. (2014), “Gofai”. In: Frankish, Keith \& Ramsey, William (orgs.). The Cambridge handbook of artificial intelligence. Cambridge, Cambridge University Press.

Boudon, Raymond. ([1992] 1995), Tratado de sociologia. Rio de Janeiro, Jorge Zahar Ed.

Boudon, Raymond. (2001), The origin of values. sociology and philosophy of beliefs. New Brunswick, Transaction Publishers.

Bowles, Samuel \& Gintis, Herbert. (2011), A cooperative species: Human reciprocity and its evolution. Princeton, Princeton University Press.

Brown, Richard H. (1987), Society as text. Essays on rhetoric, reason, and reality. Chicago, Chicago up.

BROwn, Richard H. (1990), "Rhetoric, textuality, and the postmodern turn in sociological theory”. Sociological Theory, 8: 188-197.

Bunge, Mario. (1996), Buscar la filosofía en las ciencias sociales. Madrid, Siglo XXI.

Bunge, Mario. (1999), Las ciencias sociales en discusión. Buenos Aires, Editorial Sudamericana.

Bunge, Mario. (2000), Social science under debate: A philosophical perspective. Toronto, Toronto UP.

Bunge, Mario. (2003), Emergence and convergence: Qualitative novelty and the unity of knowledge. Toronto, Toronto UP.

Bunge, Mario. (2010), Matter and mind. Heidelberg, Londres, Nova York, Springer. 
Buss, David M. (2004), Evolutionary psychology: The new science of the mind. Boston, Pearson. CaVAlli-Sforza, Luigi L \& Feldman, Marcus W. (1981), Cultural transmission and evolution: A quantitative approach. Princeton, Princeton UP.

Cerulo, Karen A. (1997), "Identity construction: New issues, new direction”. Annual Review of Sociology, 23: 385-09.

Churchland, Patricia S \& Sejnowski, Terrence J. (1993), The computational brain. Cambridge, MIT Press.

Clifford, James \& Marcus, George E. (1986), Writing culture: The poetics and politics of ethnography. Berkeley, CA, California UP.

CoAse, Ronald. (1990), The firm, the market, and the law. Chicago, Chicago up.

Coleman, James S. (1986), “Social theory, social research, and a theory of action”. American Journal of Sociology, 91: 1309-1335.

Coleman, James S. (1990), Foundations of social theory. Cambridge, Harvard Up.

Cosmides, Leda \& ToobY, John. (1987), "From evolution to behavior: Evolutionary psychology as the missing link”. In: DupRÉ, John (org.). The latest on the best: Essays on evolution and optimality. Cambridge MA, MIT Press.

DAW KIns, Richard. (1976), The selfish gene. Oxford, Oxford UP.

De WAAL, Frans. (2008), "Putting the altruism back into altruism: The evolution of empathy". The Annual Review of Psychology, 59: 279-300.

Decety, Jean \& JaCKson, Philip L. (2006), "A social neuroscience perspective on empathy". Current Directions in Psychological Science, 15: 54-58.

Dennett, Daniel. (1991), Consciousness explained. Boston, Little Brown.

Derrida, Jacques. (1967), De la grammatologie. Paris, Minuit.

Dilthey, Wilhelm. (2002), Selected Works. Princeton, Princeton up.

DUNBAR, Robin. (2009), “The social brain hypothesis and its implications for social evolution”. Annals of Human Biology, 36 (5): 562-572.

EASTERLIn, Nancy. (2012), A biocultural approach to literary theory and interpretation. Baltimore, Md., John Hopkins UP.

Eco, Umberto. (1992), “Overinterpreting text”. In: ColLINI, S. Interpretation and overinterpretation. Cambridge, Cambridge UP.

ElSTER, John. (1982), “The case for methodological individualism”. Theory and Society, 11 (4): 453-482.

Epstein, Joshua M. (2007), Generative social science: Studies in agent-based computational modeling. Princeton, Princeton UP.

FEHR, Ernst \& FisCHBACHER, Urs. (2003), “The nature of human altruism”. Nature, 425: 785-91.

Fodor, Jerry \& Pylyshyn, Zenon. (1988), "Connectionism and cognitive architecture”. Cognition, 28.

Foucault, Michel. ([1966] 1984), Las palabras y las cosas. Barcelona, Planeta. 
GadAmer, Hans-George. (2004 [1975]), Truth and method. Londres, Bloomsbury.

Gallistel, C. R\& King, Adam P. (2009), Memory and the computational brain: Why cognitive science will transform neuroscience. Nova York, Wiley and Blackwell.

Garfinkel, Harold. (1967), Studies in ethnomethodology. Englewood Cliffs, Prentice-Hall.

GARFInkeL, Harold. (2002), Ethnomethodology's program: Working out Durkeim's aphorism. Oxford, UK, Rowman \& Littlefield.

GeERTz, Clifford. (1973), The interpretation of cultures. Nova York, Basic Books.

Geertz, Clifford. (1984), "Distinguished lecture: Anti anti-relativism”. American Anthropologist, 86 (2): 263-278.

Gintis, Herbert et al. (2005), Moral sentiments and material interest: The foundations of cooperation in economic life. Cambridge MA, MIT Press.

Goffman, Erving. (1967), Interaction ritual: Essays on face-to-face behavior. Garden City, Nova York, Doubleday, Anchor Books.

GofFMAn, Erving. (1975), Frame analysis. an essay on the organization of the experience. Massachussetts, Cambridge.

Graham, Jesse et al. (2011), "Mapping the moral domain". Journal of Personality and Social Psychology, 101: 366-385.

Granovetter, Mark. (1985), "Economic action and social structure: The problem of embeddedness". American Journal of Sociology, 91: 481-510.

Grondin, Jean. ([1991] 1994), Introduction to philosophical hermeneutics. New Haven, Yale UP.

Grossberg, Lawrence. (1997), “Cultural studies, modern logics, and theories of globalization”. In: McRoвbie, A. (org.). Back to reality? Social experience and cultural studies. Manchester, Manchester UP.

Habermas, Jürgen. (2010), Teoría de la acción comunicativa. Madri, Trotta.

Habermas, Jürgen. (2002), Verdad y justificación. Madri, Trotta.

Habermas, Jürgen. (1988), La lógica de las ciencias sociales. Madri, Tecnos.

HAIDT, Jonathan \& JosEPH, Craig. (2004). "Intuitive ethics: How innately prepared intuitions generate culturally variable virtues”. Daedalus, 4: 55-66.

HaIdT, Jonathan \& Joseph, Craig. (2007), "The moral mind: How five sets of innate intuitions guide the development of many culture-specific virtues, and perhaps even modules". In: Carruthers, P. (org.). The innate mind: Vol. 3. foundations and the future. Nova York, Oxford UP.

Harcourt, Bernard E. (2012), The illusion of free markets: Punishment and the myth of natural order. Cambridge, Harvard UP.

Hayex, Friedrich (1989), "The pretence of knowledge". American Economic Review, 79: 3-7.

HAYEK, Friedrich (1944), The road to serfdom. Chicago, Chicago Up.

Невв, Donald. (1949), The organization of behavior. Nova York, Wiley.

Hechter, Michael \& Opp, Karl-Dieter. (2001), Socialnorms. Nova York, Russell Sage Foundation. 
Henrich, Joseph \& McElreath, Richard. (2007), "Dual-inheritance theory: The evolution of human cultural capacities and cultural evolution”. In: BARRETT, L. \& Dunbar, Robert (org.). Oxford handbook of evolutionary psychology. Oxford, Oxford UP.

Hernstein, Richard J. \& Murray, Charles. (1994), The bell curve. Nova York, Free Press.

Hogarth, Robin M. \& Reder, Melvin W. (1987), Rational choice: The contrast between economics and psychology. Chicago, Chicago UP.

Iacoвoni, Marco. (2008), Mirroring people: The new science of how we connect with others. Nova York, Farrar, Straus and Giroux.

INGLeharT, Ronald. (2008), "Changing values among western publics, 1970-2006: Postmaterialist values and the shift from survival values to self expression values". West European Politics, 31(1-2): 130-146.

Inglehart, Ronald. (2018), Cultural evolution. People's motivations are changing, and reshaping the world. Cambridge, Cambridge UP.

Jordan, Fiona et al. (2013), "Cultural evolution of the structure of human groups". In: RICherson, Peter \& Christiansen, Morten (orgs.). Cultural evolution: Society, technology, language, and religion. Cambridge, MA, MIT Press.

Kahneman, Daniel et al. (1982), Judgment under uncertainty: Heuristics and biases, Cambridge, Cambridge UP.

Kahneman, Daniel \& Tversky, Amos. (1979), "Prospect theory: An analysis of decision under risk". Econometrica, 47: 263-291.

KIM, Jaegwon. ([1993] 2002), Supervenience and mind. Cambridge, Cambridge UP.

Lewens, Tim. (2015), Cultural evolution: Conceptual challenges. Oxford, UK, Oxford UP.

Liu, Eric. \& Hanauer, Nick. (2011), The gardens of democracy: A new american story of citizenship, the economy, and the role of goverment. Seattle, Sasquatch Books.

Longino, Helen. (2002), The fate of knowledge. Princeton, Princeton UP.

LuCAS, Robert E. \& SARGENT, Thomas J. (1981), Rational expectations and econometric practice. Minneapolis, Minnesota UP.

Marcus, Gary. (2004), The birth of the mind. Nova York, Basic Books.

MARKs, Jonathan. (2002), What it means to be 98\% chimpanzee. Los Angeles, California UP.

MATHEW, Sarah et al. (2013), "Human cooperation among kin and close associates may require enforcement of norms by third parties”. In: Richerson, Peter \& Christiansen, Morten (orgs.). Cultural evolution: Society, technology, language, and religion. Cambridge, MA, MIT Press.

McAdams, Dan P. (2001), "The psychology of life stories". Review of General Psychology, 5 (2): 100-122.

Moll, Jodie \& Hoque, Zahirul. (2006), Rational choice theory. Methodological issues in accounting research: Theories, methods and issues. Londres, Spiramus Press.

Mouzelis, Nicos P. (1995), Sociological theory: What went wrong? Londres e Nova York, Routledge. 
Nelson, Cary et al. (1992), "Cultural studies: An introduction”. In: Grossberg, Lawrence et al. Cultural studies. Nova York, Londres, Routledge.

Newell, Allen. (1982), The knowledge level. Artificial Intelligence, 18 (1): 87-127.

Oppenheimer, Joe A. (2010), "Rational choice theory”. In: Bevir, M. Encyclopedia of political theory. Londres, Sage.

Phelps, Elizabeth. (2006), "Emotion and cognition”. Annual Review of Psychology, 57: 27-53.

Plutchik, Robert. (1987), “Evolutionary bases of empathy”. In: EISENBERG, N. \& STRAYER, J. (orgs.). Empathy and its development. Cambridge, Cambridge UP.

Polanyi, Karl et al. (1957), Trade and market in the early empires: Economies in history and theory. Nova York, Free Press.

Preston, Stephanie D. \& De WaAl, Frans. (2002), "Empathy: Its ultimate and proximate bases". Behavioral and Brain Sciences, 25: 1-72.

Reynoso, Carlos. (2000), Apogeo y decadencia de los estudios culturales: Una visión antropológica. México DF, Gedisa.

Richerson, Peter \& Boyd, Robert. (2005), Not by genes alone: How culture transformed buman evolution. Chicago, Chicago UP.

Richerson, Peter \& Christiansen, Morten (eds.). (2013), Cultural evolution: Society, technology, language, and religion. Cambridge, MA, The MIT Press.

Richerson, Peter \& Henrich, Joseph. (2012), "Tribal social instincts and the cultural evolution of institutions to solve collective action problems". Cliodynamics, 3: 38-80.

Ricoeur, Paul. (1965), De l'interprétation. essai sur Freud. Paris, Seuil.

Ricoeur, Paul. (1975), “La fonction herméneutique de la distanciation”. Exegesis. Problémes De Méthode Et Exercises De Lecture. Neuchâtel, Delachaux Et Niestle, 179-200.

Ricoevr, Paul. (1977), "La structure symbolique de l'action”. Actes De La 14e Conférance Internationale De Sociologie Des Religions. Lille, Secrétariat C.I.S.R., 35.

Ricoeur, Paul. (1983), Temps et récit 1. L’intrigue et le récit historique. Paris, Seuil.

Ricoeur, Paul. ([1986] 2001), Del texto a la acción. ensayos de hermenéutica II. México, Fondo de Cultura Económica.

Ridley, Matt. (2015), The evolution of echonomy. The evolution of everything: How new ideas emerge. Nova York, HarperCollins.

Rizzolati, Giacomo et al. (1996), "Premotor cortex and the recognition of motor actions". Cognitive Brain Research, 3 (2): 131-141.

Rorty, Richard. (1981), Philosophy and the mirror of nature. Princeton, Princeton UP.

SARgent, Thomas J. (1987), Macroeconomic theory. Nova York, New York Academic Press.

SCHLUCHTER, Wolfgang. (1981), The rise of western rationalism max weber's developmental history. Berkeley; Los Angeles; Londres, University of California Press.

SснÜтz, Alfred. ([1932] 1967). The phenomenology of the social world. Evanston IL, Northwestern UP. 
Sejnowski, Terrence et al. (1988), Computational neuroscience. Science, 241: 1299-306.

ShamaY-Tsoory, Simone. (2011), “The neural bases for empathy”. Neuroscientist, 17 (1): 18-24.

Shubiк, Martin. (1984), A game theoretic approach to political economy. Cambridge, MA, MIT Press.

Shweder, Richard et al. (1987), "Culture and moral development". In: KaGAn, J \& Lamb, S. (org.). The emergence of morality in young children. Chicago, Chicago UP.

SHWEDER, Richard et al. (1997). "The 'big three' of morality (autonomy, community, and divinity), and the 'big three' explanations of suffering”. In: BRAND, A. \& Rozin, P. (orgs.). Morality and health. Nova York, Routledge.

Sloman, Steven \& Fernbach, Philip. (2017), The knowledge illusion. Nova York, Riverhead.

SWEDBERG, Richard. (1994), "Markets as social structures”. In: SMELSER, Neil \& SwEDBERG, Richard (orgs.). The handbook of economic sociology. Princeton, Princeton UP.

Tiger, Lionel \& Fox, Robin. (1971), The imperial animal. Nova York, Holt, Rinehart and Winston.

Tomasello, Michael et al. (2005), "Understanding and sharing intentions: The origins of cultural cognition”. Behavioral and Brain Sciences, 28: 675-735.

Turchin, Peter. (2013), “The puzzle of human ultrasociety: How did large-scale complex societies evolve?”. In: Richerson, Peter \& Christiansen, Morten (orgs.). Cultural evolution: Society, technology, language, and religion. Cambridge, MA, MIT Press.

Turchin, Peter. (2016), Ultrasociety: How 10,000 years of war made humans the greatest cooperators on earth. Chaplin, Beresta Books.

Turco, Catherine J. \& Zuckerman, Ezra W. (2017), "Verstehen for sociology: Comment on Watts”. American Journal of Sociology, 122 (4): 1272-91.

WatTs, Duncan J. (2014), "Common sense and sociological explanations". American Journal of Sociology, 120: 313-51.

Weber, Max ([1913] 1992), "Essai sur quelques catégories de la sociologie compréhensive”. In: Weber, Max. Essais sur la théorie de la science. Paris, Plon.

Weber, Max. ([1922] 1984), Economía y sociedad. México, Fondo de Cultura Económica.

Wilson, David S. (2008), "Evolution 'for the Good of the Group”. American Scientist, 96 (2): 380-389.

WiLson, David S. (2015), Does altruism exist? culture, genes and the welfare of others. New Haven CT, Yale UP.

Woolgar, Steve. (1986), “On the alleged distinction between discourse and praxis”. Studies of Science, 16 (2): 309-17. 


\section{Resumo}

Duas metáforas históricas sobre o problema do sentido da ação

O presente artigo descreve duas grandes tendências de abordagem do problema sociológico do sentido da ação. Elas podem ser melhor compreendidas fazendo uso de duas metáforas intuitivas. Trata a primeira da "mente como um computador", e a segunda do "mundo como um texto". Descrevem-se de modo geral os supostos filosóficos de cada tendência e os seus principais déficits ontológicos, epistemológicos e metodológicos. Em seguida, são apresentadas as suas convergências implícitas, ilustradas em três déficits teóricos: o dualismo, o atomismo e o holismo. $\mathrm{O}$ artigo ressalta a importância da pesquisa interdisciplinar, incluindo nela as chamadas ciências biossociais para a superação desses déficits.

Palavras-chave: Sentido da ação; Teoria da escolha racional; Hermenêutica; Interdisciplinaridade; Dualismo; Atomismo; Holismo.

\section{Abstract}

Two historical metaphors about the problem of action's meaning

This paper describes two broader tendencies about the sociological problem of action's meaning. They can be better explained using two intuitive metaphors. The first one is "the mind like a computer", and the second one is "the world like a text". The paper shows, in a general approach, the basic postulates of each tendency and their main ontological, epistemological and methodological weaknesses. Then, it will show the implicit convergences, illustrated with three main theoretical flaws: dualism, atomism, and holism. The paper stresses the importance of interdisciplinary research, including the so-called biosocial sciences, to override these flaws. Keywords: Action's meaning; Rational choice theory; Hermeneutic; Interdisciplinary research; Dualism; Atomism; Holism.

Texto recebido em 15/4/2019 e aprovado em 14/4/2020.

DOI: $10.11606 / 0103-2070 . t s .2020 .156889$.

ERnesto Mora Forero é professor e pesquisador nas áreas de teoria social, cognição social e narrativa e cognição social. Possui doutorado em sociologia pela Universidade de São Paulo, e mestrado em filosofia pela Pontificia Universidad Javeriana (Bogotá, Colômbia). Recentemente, realizou pesquisas de pós-doutorado no Instituto de Estudos da Linguagem (IEL/Unicamp) e a Utrecht Universitait (Holanda) sobre a cognição social a partir de narrativas. E-mail: juanernestomora@gmail.com. 